\title{
Ações de formação docente institucionais: quais as contribuições para a constituição do docente-bacharel?
}

\author{
Conceição de Maria Pinheiro Barros a \\ Ana Maria lorio Dias ${ }^{b}$ \\ Augusto Cézar de Aquino Cabral ${ }^{c}$
}

\section{Resumo}

Este estudo tem por objetivo avaliar as contribuições de ações de formação docente institucionais para a constituição do docente-bacharel. Desenvolveu-se uma investigação qualitativa e descritiva e estudo de casos múltiplos. Utilizaram-se as técnicas análise documental, observação participante e questionário. Participaram da pesquisa 37 docentes-bacharéis que atuam na Universidade Federal do Ceará (Brasil). No processo de interpretação dos resultados recorreu-se à Análise Hermenêutica do Conteúdo. Como principais resultados, tem-se: as ações de formação docente institucionais colaboram para a constituição do docente-bacharel por oferecer subsídios para a produção de conhecimentos pedagógicos e propiciam mudanças de paradigmas para a atuação do bacharel como docente no que se refere aos processos de ensino e aprendizagem. Porém, existem lacunas relacionadas às necessidades específicas do bacharel para que desenvolva saberes da docência. Palavras-chave: Formação docente. Ações de formação docente institucionais. Docente-bacharel.

\section{Introdução}

A docência universitária emerge como possível área de atuação profissional para o bacharel, embora este não possua formação voltada para o ensino. As instituições universitárias exigem, para o ingresso, titulação específica e stricto sensu. O

\footnotetext{
a Universidade Federal do Ceará, Fortaleza, CE, Brasil.

b Universidade Federal do Ceará, Fortaleza, CE, Brasil.

c Universidade Federal do Ceará, Fortaleza, CE, Brasil.
} 
candidato à docência também deve possuir conhecimentos inerentes à área na qual pretende lecionar e preparo para a docência em cursos de pós-graduação stricto sensu, atendendo às determinações da Lei de Diretrizes de Bases da Educação Brasileira (LDB) (BRASIL, 1996): "Consideramos fundamental, nas instituições que acolhem esse profissional, a existência de ações com o intuito de oferecer espaços de reflexão e formação pedagógica aos docentes" (BARROS; DIAS, 2016, p. 65).

Também, de acordo com esse posicionamento, Pimenta e Anastasiou (2014, p. 37) afirmam que "[...] os professores ingressam em departamentos que atuam em cursos aprovados, em que já estão estabelecidas as disciplinas que ministrarão". Não se exigem conhecimentos específicos da docência. Esse professor "[...] não tem formação voltada para processos de ensino e de aprendizagem, pelos quais é responsável, quando inicia sua carreira acadêmica" (ALMEIDA, 2012, p. 32). Consideramos que "a preparação do professor não se esgota no momento da formação inicial nos cursos de graduação, nos cursos de licenciatura ou nos cursos de pós-graduação" (OLIVEIRA JÚNIOR; LINHARES; KARWOSKI, 2018, p. 75), mas de qualificação contínua para atuação na educação superior.

Emerge o seguinte questionamento: quais são as contribuições das ações de formação docente institucional para a constituição do docente-bacharel? A Universidade possui compromisso de contribuir para a formação de professores (VASCONCELOS, 2000), pois a docência não se desenvolve de forma desvinculada da instituição. É necessário que professores encontrem espaços de elaboração de saberes e práticas que potencializem a ação pedagógica por meio de uma política institucional. Entretanto, essa formação pode assumir “[...] diferentes perspectivas: suprimento, atualização, treinamento, aprofundamento, pesquisa [...] para formação complementar à inicial considerada, na maioria das vezes, precária" (OLIVEIRA JÚNIOR; LINHARES; KARWOSKI, 2018, p. 81). As Instituições de Ensino Superior (IES) podem/devem realizar ações formativas que colaborem para a constituição do bacharel como professor.

Este artigo aborda pesquisa que tem como objetivo geral avaliar as contribuições de ações de formação docente institucionais para a constituição do docente-bacharel e como objetivos específicos: identificar aspectos positivos e lacunas das ações institucionais de formação docente, na percepção do docente-bacharel e conhecer as contribuições das ações do programa de formação docente da Universidade para a constituição de conhecimentos pedagógicos.

Considera-se sua relevância por integrar a avaliação das ações de formação para os docente-bacharéis, ofertadas por Universidade, contribuir para aprofundamento 
de discussões sobre formação pedagógica para docência na educação superior destinada àqueles que não possuem saberes pedagógicos e apresentar subsídios a serem considerados para as necessidades específicas desse profissional.

\section{Desafios da formação do docente-bacharel para atuar na educação superior}

Profissionais de diversas áreas se inserem na carreira docente, a partir das suas atividades, tendo motivações variadas, muitas vezes, sem preparação adequada para atuar como educador (PIMENTA; ANASTASIOU, 2014). Discussões atuais abordam a necessidade de conhecimentos pedagógicos para atuação na educação superior (OLIVEIRA JÚNIOR; LINHARES; KARWOSKI, 2018; CARNEIRO et al., 2018). A titulação não indica que o bacharel esteja preparado para desempenhar seu papel em sala de aula, pois a profissão docente "[...] está marcada por intensificação de quantificação de tarefas e uma complexidade cada vez maior". (OLIVEIRA JÚNIOR; LINHARES; KARWOSKI, 2018, p. 81).

Persiste a tradição de se considerar que um profissional qualificado e experiente em uma determinada área está apto a desenvolver atividades docentes e, não raro, profissionais renomados participam de concursos para atuação em IES sem conhecimentos pedagógicos. "Na formação do professor, é preciso saberes específicos para uma boa prática profissional, entre eles os saberes pedagógicos" (OLIVEIRA, 2015, p. 36), que envolvem conhecimentos da Didática, como principal campo de estudos da Pedagogia (LIBÂNEO, 2013), além de outros também ligados à Ciência Pedagógica. Para Saviani (1996) os saberes determinados pela educação e sua inserção no processo formativo docente definem-se conforme o tipo de educação pretendida. Discutiremos mais adiante a formação docente para a educação superior, bem como a constituição docente e conhecimentos pedagógicos, focalizando o docente bacharel.

\subsection{Formação docente para a educação superior}

Na educação superior, estabeleceu-se o termo pedagogia universitária, objetivando reunir questões do processo de ensino e de aprendizagem (CUNHA, 2010; PIMENTA; ANASTASIOU, 2014), a qual “[...] se distingue da pedagogia em geral pelo seu interesse em compreender o processo de aprendizagem das pessoas adultas na sua trajetória de formação profissional" (CÁRIA; SILVA, 2018, p.29).

Essa temática não tem sido situada no cerne da legislação nacional, deixando um hiato que abre a probabilidade de inserção de profissionais de áreas diversas, sem formação pedagógica, na docência universitária. A LDB estabelece que 
"a preparação para o exercício do magistério superior far-se-á em nível de pós-graduação, prioritariamente em programas de mestrado e doutorado" (BRASIL, 1996, p. 22).

Não houve uma preocupação em regulamentar a formação docente para a educação superior. A Resolução $\mathrm{n}^{\circ}$. 12/1983 menciona que a qualificação docente para o magistério superior do Sistema Federal de Ensino será realizada por meio de cursos de especialização e aperfeiçoamento (BRASIL, 1983). Ressaltamos o termo "qualificação" utilizado para referir-se à formação docente. No âmbito profissional, o vocábulo é aplicado para oferecer condições à pessoa para exercício de cargo específico. Qualificar não promove formação integral, nem, necessariamente, é complementar à determinada constituição profissional. Essa denominação não atende às necessidades formativas do educador universitário, especialmente como aperfeiçoamento.

A LDB destaca que "o notório saber, reconhecido por universidade com curso de doutorado em área afim, poderá suprir a exigência de título acadêmico" (BRASIL, 1996, p. 36). A Resolução CNE/CES, nº. 3, de 5 de outubro de 1999, ao fixar "[...] condições de validade dos certificados de cursos presenciais de especialização" (BRASIL, 1999, p. 1) determina carga horária mínima de 360 horas para a conclusão do curso. $\mathrm{O}$ termo utilizado permanece como qualificação e, o mais agravante, não prevê carga horária mínima para formação pedagógica, mas somente a garantia de enfoque pedagógico.

A Resolução CNE/CES n ${ }^{\circ}$. 1, de 3 de abril de 2001, determina normas para o funcionamento de cursos de pós-graduação (BRASIL, 2001). Ao revogar a Resolução 3/99 (BRASIL, 1999) excluiu o parágrafo primeiro do Art. $5^{\circ}$, que prenunciava inclusão de disciplina de metodologia de ensino na pós-graduação lato sensu.

A Resolução $n^{\circ}$. 12/83 estabelece que, das 360 horas mínimas para a duração do curso, somente o mínimo de "[...] 60 (sessenta) horas da carga horária serão utilizadas com disciplinas de formação didático-pedagógica, devendo o restante ser dedicado ao conteúdo específico do curso, incluindo iniciação à pesquisa" (BRASIL, 1983, p.2). Notamos a desvalorização dos conhecimentos docentes destacando-se a pesquisa. Além disso, cursos de especialização constituem uma pós-graduação Lato Sensu, de mais curta duração e mais técnica, e que é diferente da pós-graduação Stricto Sensu, que engloba Mestrado e Doutorado, ambos mais direcionados a quem deseja trilhar uma carreira acadêmica. 


\subsection{Constituição docente e conhecimentos pedagógicos}

A ideia de formação do professor pode ser renovada por meio do conhecimento do trabalho docente (TARDIF, 2013) e a constituição docente ocorre, normalmente, por meio da prática. Lacerda $(2015$, p. 97) pondera que o "[...] professor do ensino superior reconstrói suas experiências, às vezes, pela intuição e, em outros momentos, pela reelaboração dos conhecimentos tecidos nas trajetórias pessoal e profissional". Essa constituição docente enseja saberes e métodos de ensino que ultrapassem a transmissão de informações, proporcionem ao educando descobertas por meio de suas experiências e superem a educação bancária, caracterizada pela memorização de conteúdo, sem que o educando compreenda o seu significado, considerando o professor como único detentor do conhecimento; os alunos são como recipientes a serem preenchidos (FREIRE, 1996; 1987).

Vasconcelos (2000) afirma que a universidade é responsável pela formação de seus docentes, embora considere importantes os conhecimentos adquiridos nos programas de pós-graduação. Almeida (2012) reputa que as instituições possuem, como principal função, qualificar o docente por meio de políticas formativas. Implementam-se ações de formação docente nas IES, como: institucionalização de programas de formação docente e definição de princípios de formação universitária docente (OLIVEIRA JÚNIOR; LINHARES; KARWOSKI, 2018).

Tais ações são mais insuficientes ainda para suprir as lacunas relativas aos saberes pedagógicos de docentes-bacharéis. Deve-se considerar a importância prioritária da formação docente (ALMEIDA; PIMENTA, 2011), como parte de política institucional, criação e permanência de espaços direcionados à profissionalização de professores (ANASTASIOU, 2011). Conforme Behrens e Junges (2018), as instituições devem ser lócus dessa formação alicerçada na inovação, na colaboração, e na clareza acerca do papel docente na mediação do conhecimento na universidade.

\section{Caminhos metodológicos}

Utilizamos a abordagem qualitativa compreendida como "[...] um processo de reflexão e análise da realidade através da utilização de métodos e técnicas para compreensão detalhada do objeto de estudo em seu contexto histórico[...]" (OLIVEIRA, 2010, p. 37). Classifica-se como descritiva, pois analisa os fatos, realiza descrição detalhada e interpreta em profundidade a realidade pesquisada (OLIVEIRA, 2010, p. 68). Desenvolvemos um estudo de casos múltiplos considerado como a reunião de diversos estudos de casos únicos, vinculados por métodos investigativos comuns e realizado por meio de diversas fontes de 
evidências (VASCONCELOS, 2016). Os professores foram considerados casos e utilizamos uma diversidade metodológica.

O campo da pesquisa foi o programa de formação docente da Universidade Federal do Ceará (UFC). A escolha desta academia justifica-se pelo fato de que ela possui as características necessárias ao alcance dos objetivos: ser universidade pública situada no Município de Fortaleza, Ceará; possuir em seu corpo docente profissionais bacharéis e programa de formação docente.

O Programa Comunidade de Cooperação e Aprendizagem Significativa (CASa) foi fundado pela Pró-Reitoria de Graduação da UFC. Essa IES, inicialmente, ofertava apenas a disciplina de Didática do Ensino Superior para professores iniciantes; posteriormente, foi criado o programa Rede de Valorização do Ensino Superior (RVES), que atendia a docentes, discentes e servidores técnico-administrativos lotados nas coordenações de cursos, fundamentado na ação-reflexão-ação, e/ ou reflexão-ação-reflexão, promovia formação docente, a partir da descrição de práticas cotidianas, possibilitando " refletir coletivamente sobre o que se faz e pôr-se na roda, e deixar-se conhecer, e expor-se" (PIMENTA; ANASTASIOU, 2014, p. 113): "O \{Projeto CASa nasceu em 2009, a gente tinha um programa chamado Programa Rede de Valorização do Ensino Superior [...] e a ideia foi ampliar" (OBSERVAÇÃO PARTICIPANTE, 2014 - o que está entre chaves -\{\} - foi um acréscimo nosso, para melhor compreensão).

Atualmente, o CASa "atende, obrigatoriamente, pessoas que estão em período probatório, mas ele é aberto a qualquer docente [...] que queira participar" (OBSERVAÇÃO PARTICIPANTE, 2014). Suas atividades são organizadas em três dimensões: encontros presenciais, ambiências temáticas e curso de docência, Tecnologias da Informação e Comunicação. A formação docente inclui-se no eixo estratégico do Plano de Desenvolvimento Institucional (PDI) da Universidade (UNIVERSIDADE FEDERAL DO CEARÁ, 2012) (Quadro 1).

A UFC, então, institucionalizou ações de formação docente, visando à consolidação do CASa, com avaliação das atividades ofertadas, inclusão do docente como principal agente de sua formação e intensificação da participação dos professores em estágio probatório.

Os colaboradores desta pesquisa foram constituídos de representantes docentes, conforme os critérios: ser graduado na modalidade de bacharelado; ter experiência mínima de cinco anos na docência universitária; atuar como docente na UFC; ter participado ou estar participando do programa CASa; ter disponibilidade e 
Quadro 1. Objetivos e estratégias

\begin{tabular}{|c|c|}
\hline Objetivo & Estratégia \\
\hline $\begin{array}{l}\text { Consolidar ações de promoção de } \\
\text { desenvolvimento e formação docente } \\
\text { continuada. }\end{array}$ & $\begin{array}{l}\text { Consolidar as estratégias de } \\
\text { desenvolvimento e formação docente } \\
\text { na UFC, promovidas pela CASa em } \\
\text { articulação com outras ações existentes. }\end{array}$ \\
\hline $\begin{array}{l}\text { Avaliação periódica das atividades de } \\
\text { desenvolvimento e formação continuada } \\
\text { promovidas com e para os docentes. }\end{array}$ & $\begin{array}{l}\text { Buscar subsídios nos relatórios das } \\
\text { Comissões Setoriais de Avaliação } \\
\text { Docente de cada Unidade Acadêmica } \\
\text { e da Coordenadoria de Planejamento } \\
\text { e Avaliação de Programas e Ações } \\
\text { Acadêmicas/ Sistema Nacional de } \\
\text { Avaliação da Educação Superior (SINAES). }\end{array}$ \\
\hline $\begin{array}{l}\text { Engajamento, protagonismo e cooperação na } \\
\text { formação docente. }\end{array}$ & $\begin{array}{l}\text { Articulação entre os programas de } \\
\text { formação docente e a gestão das } \\
\text { unidades acadêmicas. }\end{array}$ \\
\hline $\begin{array}{l}\text { Potencializar as atividades de formação } \\
\text { docente durante o estágio probatório. }\end{array}$ & $\begin{array}{l}\text { Acolher e acompanhar os professores } \\
\text { recém-ingressados na UFC. }\end{array}$ \\
\hline
\end{tabular}

Fonte: Univesidade Federal do Ceará (2012).

aceitar a proposta da pesquisa. Foram convidados 144 docentes-bacharéis e 37 aceitaram participar da pesquisa, assim distribuídos: 23 docentes-bacharéis que concluíram atividades de formação docente e 14 que estavam participando de ações formativas docentes. A geração de dados ocorreu no período de 2014 a 2016. Segundo Gaskell (2005), na pesquisa qualitativa, o termo "seleção" é utilizado em substituição ao vocábulo "amostragem", já que esta expressão indica uma coleta de informações na qual a análise de resultados é feita por meio de uma amostra estatística sistemática da população.

Foram utilizadas três fontes de evidências para a geração de dados, que corresponderam às técnicas, aos instrumentos e aos procedimentos específicos (VASCONCELOS, 2016), conforme Quadro 2.

A pesquisa documental foi considerada adequada ao alcance dos objetivos, pela composição de uma diversidade de materiais examinados e por contribuir para a avaliação proposta. $\mathrm{O}$ estudo documental foi realizado a partir de fontes primárias, relativas à legislação brasileira e aos documentos institucionais da UFC:

a) Documentos legais/Educação: Lei de Diretrizes e Bases da Educação Nacional, Lei ${ }^{\circ}$ 9.394, de 20 de dezembro de 1996; Resolução CNE/CES $\mathrm{N}^{\mathrm{o}} 1$, de 3 de abril de 2001; Resolução CNE/CES n ${ }^{\circ}$. 3, de 5 de outubro de 1999; Resolução nº 12/1983, de 6 de outubro de 1983. 
Quadro 2. Fontes de evidências, técnicas, instrumentos de geração de dados e procedimentos.

\begin{tabular}{|l|c|c|c|}
\hline Fontes & Técnicas & Instrumento & Procedimentos \\
\hline $\begin{array}{l}\text { Pesquisa } \\
\text { documental de } \\
\text { fontes primárias }\end{array}$ & $\begin{array}{c}\text { Análise de } \\
\text { documentos }\end{array}$ & $\begin{array}{c}\text { Roteiro } \\
\text { documental }\end{array}$ & $\begin{array}{c}\text { Analise e registro das } \\
\text { observações. }\end{array}$ \\
\hline Observação & $\begin{array}{l}\text { Observação } \\
\text { participante }\end{array}$ & $\begin{array}{c}\text { Roteiro de } \\
\text { observação } \\
\text { participante }\end{array}$ & $\begin{array}{c}\text { Inscrição nas atividades do CASa. } \\
\text { Registro em diário de campo e } \\
\text { uso de gravador de voz. }\end{array}$ \\
\hline Questionário & $\begin{array}{c}\text { Questionário } \\
\text { misto }\end{array}$ & $\begin{array}{c}\text { Questionário on de horas: 134h } \\
\text { line }\end{array}$ & $\begin{array}{c}\text { Software e ferramenta de } \\
\text { pesquisa online denominado } \\
\text { SurveyMonkey, no períndo de } \\
\text { 20 de setembro de 2015 a 8 de } \\
\text { dezembro de 2016. }\end{array}$ \\
\hline
\end{tabular}

Fonte: Elaborado pelos autores (2019).

b) Documentos institucionais/UFC: Carta de apresentação - CASa; Plano de Desenvolvimento Institucional - 2013-2017; Relatório de Autoavaliação Institucional da Universidade Federal do Ceará ano base 2009 (UNIVERSIDADE FEDERAL DO CEARÁ, 2010).

Realizamos observação participante, que "é uma das mais importantes fontes de informações em pesquisas qualitativas em educação" (VIANNA, 2007, p. 12), classificada como natural, pois os pesquisadores integram o grupo investigado (OLIVEIRA, 2010).

A técnica de questionário foi utilizada para gerar informações sobre expectativas, percepções e situações vivenciadas pelos docentes (OLIVEIRA, 2010), composto de dez questões, sobre o programa CASa, a saber: motivos para participar do programa, expectativas, contribuições para a constituição docente e conhecimentos pedagógicos, aspectos positivos, lacunas e sugestões de melhoria.

Utilizamos a Análise Hermenêutica do Conteúdo, visto que a hermenêutica desafia a compreensão interpretativa-reprodutiva e defende a inexistência de interpretação correta e definitiva (SCHWANDT, 2006). Recorremos às etapas de análise do conteúdo (BARDIN, 2009), levando em conta a multidisciplinaridade e a interdisciplinaridade. À luz da hermenêutica, as informações receberam significados fundamentadas no levantamento teórico, conforme categorias apresentadas no Quadro 3 
Quadro 3. Categorias e subcategorias

\begin{tabular}{|l|c|}
\hline Categorias & Subcategorias \\
\hline $\begin{array}{l}\text { Formação docente para educação } \\
\text { superior }\end{array}$ & $\begin{array}{r}\text { Motivação para participar do Programa CASa } \\
\text { Atividades do Programa CASa } \\
\text { Aspectos positivos e lacunas }\end{array}$ \\
\hline $\begin{array}{l}\text { Constituição docente e construção } \\
\text { de conhecimentos pedagógicos }\end{array}$ & $\begin{array}{c}\text { Necessidades específicas de formação para o } \\
\text { docente-bacharel }\end{array}$ \\
& $\begin{array}{c}\text { Expectativas e resultados das ações para a } \\
\text { constituição docente } \\
\text { Contribuições das açôes para a construção de } \\
\text { conhecimentos pedagógicos }\end{array}$ \\
\hline
\end{tabular}

Fonte: Elaborado pelos autores (2019).

A interpretação dos dados gerados visou à compreensão, por meio da descrição e da leitura crítica de pontos fundamentais, para o alcance dos objetivos da pesquisa (PALMER, 2006). Apresentaremos, a seguir, os dados essenciais, em quadros reunindo percepções comuns dos casos únicos considerados (VASCONCELOS, 2016).

\section{Resultados e discussão}

Os motivos que levaram os docentes a participarem do Programa CASa, foram: aquisição e/ou aperfeiçoamento de conhecimentos pedagógicos, contribuição para seu desenvolvimento profissional docente, troca de experiências com colegas professores, enriquecimento do currículo e melhoria da prática docente. O principal fator refere-se ao cumprimento de exigência no período de estágio probatório. "As atividades da CASa são abertas a todos os docentes da UFC, discentes e para a comunidade, entretanto, é obrigatória para docentes em estágio probatório" (UNIVERSIDADE FEDERAL DO CEARÁ, 2013, p. 1, grifo do autor), exigência da Lei 8.112/90 (BRASIL, 1990). A aptidão do professor ingressante na Universidade é avaliada verificando-se a preparação de suas atividades educacionais e o cumprimento de 64 horas formativas. Mas, afinal, qual é a percepção dos participantes desta pesquisa sobre as contribuições do programa para a constituição do bacharel como docente?

Focalizamos nas atividades do programa que os professores participavam ou haviam concluído, quais as mais relevantes para a sua atuação. A atividade mais referenciada foi a intitulada Mentores da Docência, que, conforme a Universidade Federal do Ceará (2013), os recém-admitidos fazem homenagens àqueles que foram importantes em suas vidas, inspirando-os à docência: “[...] traz o exemplo e a experiência dos professores homenageados, o que nos inspira a aperfeiçoar, 
cada vez mais, nosso trabalho" (DOCENTE-BACHAREL 61). A constituição do educador é influenciada pelo exemplo de outros professores com os quais conviveram, corroborando a ideia de que "Los profesores son actores esenciales en el sistema educativo y en el logro de una buena enseñanza" (HERRERA; FERNÁNDEZ; SEGUEL, 2018, p. 164).

AAmbiência Temática foi outra atividade selecionada pelos respondentes; nessa ação, os professores criam e gerenciam um grupo com o objetivo de constituir conhecimentos sobre tema voltado para o desenvolvimento, a formação e a atuação docente. Os Encontros Didáticos, também indicados pelos professores, são espaços promovidos com paticipação de professores-pesquisadores de Didática, visando refletir acerca da prática de ensino (UNIVERSIDADE FEDERAL DO CEARÁ, 2013). Destacaram-se os cursos ofertados em parceria com a Pró-Reitoria de Gestão de Pessoas (PROGEP), também voltados para a Didática, o que reafirma a importância de uma ação institucional articulada, em prol do desenvolvimento de saberes pedagógicos. O Docente-Bacharel 32 comentou que busca "melhorar a formação didática, uma vez que na formação do bacharelado, não alcança a discussão pedagógica", esta opinião remete à Didática como disciplina essencial (OLIVEIRA, 2015; LIBÂNEO, 2013) para a formação do professor egresso do bacharelado:

A disciplina Didática do Ensino Superior, observada, realizou-se na Faculdade de Educação da UFC em parceria com o CASa. Participaram professores bacharéis do CASa, graduados em áreas, como: Jornalismo, Finanças, Direito, Ciências Atuariais e Secretariado Executivo. Com carga horária de 64 horas, objetivou refletir e analisar a realidade do contexto histórico e sociopolítico do ensino nas universidades e demais IES, no âmbito nacional e estadual (OBSERVAÇÃO PARTICIPANTE, 2014).

Observamos as expectativas dos docentes em relação à construção de conhecimentos pedagógicos:

[...] estou aqui tentando fazer perguntas e encontrar respostas porque a minha área de conhecimento não dá conta desse grande questionamento que são os saberes docentes. Esta é a minha indagação: que saberes docentes são necessários ao professor do ensino superior? (OBSERVAÇÃO PARTICIPANTE, 2014).

Cada professor(a) participante foi denominado(a) de "Docente-Bacharel" seguido de um número natural que representa a ordem de resposta ao questionário. 
Existe uma inquietação dos bacharéis, que se tornam docentes, relacionada aos saberes docentes na educação superior. Não é somente conhecer os saberes, mas aplicá-los e facilitar a aprendizagem do educando. Isso requer conhecimentos de Didática que "investiga os fundamentos, condições e modos de realização da instrução e do ensino." (LIBÂNEO, 2013, p. 25).

A Docência Integrada às Tecnologias da Informação e Comunicação (DTIC), uma das atividades das quais os professores participaram, constituiu-se um "espaço formativo gerenciado por docentes da UFC Virtual. Curso de 64h de formação presencial e virtual que auxilia os professores a utilizarem recursos tecnológicos na prática docente" (UNIVERSIDADE FEDERAL DO CEARÁ, 2013).

Comparando as atividades realizadas com as ações consideradas mais relevantes para a sua constituição docente, observamos algumas contradições. A maioria dos participantes, representada por 12 professores, indicou a importância dos encontros de Didática, porém, somente seis realizaram essa atividade. Um dos que participaram dessa ação justificou: "Dentre os que eu participei até o momento, os encontros de didática foram muito esclarecedores, possibilitaram interagir com professores de várias áreas do conhecimento, o que é muito enriquecedor (DOCENTE-BACHAREL 27).

Os Seminários Pedagógicos foram assinalados como relevantes para a docência por nove respondentes, mas apenas quatro participaram dessa ação. Sobre a importância dessa ação, um dos respondentes afirmou: "os seminários pedagógicos abordam mais especificamente a questão da didática, suscitando aprendizados, dicas e discussões sobre a prática docente" (DOCENTE-BACHAREL 6).

Nas ações "Mentores da Docência", "Ambiência Temática" e cursos da PROGEP, há uma convergência com a quantidade de professores que realizaram tais eventos, para o que encontramos justificativa como a explicitada pelo Docente-Bacharel 13: "Porque ajuda a refletir sobre nossas práticas em sala, assim como colabora com novas técnicas na exposicão e avaliação dos alunos". Corrroborando essa percepção, o Docente-Bacharel 14 explicou: "Porque nesses espaços há debate e troca de experiência, que possibilitam o desenvolvimento de um olhar plural sobre a atuação docente". Os participantes percebem a importância dos saberes para a docência, ainda que de forma intuitiva. Para Lacerda (2015), às vezes a reconstrução de experiências na trajetória docente ocorre por meio da intuição.

Sobre os aspectos positivos, os professores consideram que as ações da Instituição possibilitam integração com os demais colegas e com o educando: 
Acho que o programa CASA contribui para a integração dos novos docentes e para o desenvolvimento de competências pedagógicas fundamentais para que os docentes tenham um bom desempenho (DOCENTE-BACHAREL 8).

O Projeto Casa, nas suas mais variadas áreas de atuação, propicia troca de experiências entre os envolvidos no projeto, melhoria da didática do ensino e melhoria na relação entre professor-aluno, conhecimento sistemático entre o ensinar e o aprender, dentre outras (DOCENTE-BACHAREL 18).

Evidencia-se a complexidade da docência universitária (TARDIF, 2013; CÁRIA; SILVA, 2018) refletida na subjetividade da relação educador-educando e requer competência didática (LIBÂNEO,2013). Considerou-se que o programa colabora para a inovação:

É importante inovar no ensino, de modo a conquistar a atenção e interesse dos alunos pelas disciplinas. O uso de tecnologias e de técnicas didáticas não convencionais pode ser aperfeiçoado/desenvolvido através do Programa CASa (DOCENTE -BACHAREL 8).

O domínio de competências tecnológicas possibilita o desenvolvimento de conhecimentos e o resultado de sua utilização para a aprendizagem depende de como o professor maneja as ferramentas (HERRERA; FERNÁNDEZ; SEGUEL, 2018). Identificamos, também, insatisfação com o programa: "Não vi muita importância dos eventos de que eu participei para a minha área de atuação como docente" (DOCENTE-BACHAREL 10). O Docente-Bacharel 18 acentuou: "Dos eventos de que participei, não vi muita contribuição para a docência na minha área". Para o Docente-Bacharel 14:

De início, o programa desperta expectativas de aperfeiçoamento e aprofundamento sobre questões relacionadas, direta ou indiretamente, à docência, mas seu formato e as demandas da Universidade, com o passar do tempo, desviaram meu interesse.

O Docente-Bacharel 20 assinalou: "Acho que a CASa traz excelentes propostas para formação, mas acho a carga-horária exigida alta em relação às demandas de atividades que nós, professores, temos na UFC". As diversas atribuições que a docência universitária requer se tornam empecilho para que os professores se dediquem à formação. Para que as ações de formação docente contribuam para a 
constituição do bacharel como educador universitário, é necessária a implementação de políticas formativas, que considerem as necessidades específicas do bacharel aos conhecimentos pedagógicos. "[...] A formação para a docência deve ser considerada como principal fundamento para a atuação do professor bacharel na educação superior" (BARROS; DIAS, 2016, p. 45), entretanto, tornou-se um dos principais desafios “[...] de muitos profissionais da educação, principalmente daqueles oriundos do curso de bacharelado, pois não tiveram uma formação direcionada para o exercício da atividade docente" (CARNEIRO et. al., 2018).

As necessidades específicas de formação para o docente-bacharel ressaltadas foram: conhecimentos didáticos, estratégias de ensino, avaliação e práticas de ensino de conteúdo específico. O domínio de seu campo formativo não garante eficácia no ensino pois "a lacuna relativa aos conhecimentos pedagógicos, existente na formação recebida pelo professor bacharel, tem como consequência constantes desafios enfrentados em sua prática de ensino" (BARROS; DIAS, 2016, p. 46). Um dos participantes destacou: "Devido à minha formação ser em bacharelado, busco mais conhecimentos na área de didática que possam me auxiliar na elaboração e desenvolvimento das minhas aulas" (DOCENTEBACHAREL 30). Percebemos a preocupação deste participante relacionada às "[...] concepciones sobre aprendizaje, enseñanza y evaluación, entendiendo que en la práctica docente estas se interconectan [...]" (HERRERA; FERNÁNDEZ; SEGUEL, 2018, p. 170).

Destacou-se pouca atenção oferecida à pesquisa; segundo Freire (1996, p. 16), "não há ensino sem pesquisa e pesquisa sem ensino. Esses que-fazeres se encontram um no corpo do outro". A busca constante deve estar na atuação do docente, ao compreender que ele nunca sabe tudo e admitir sua ignorância ante os desafios que o rodeiam.

Sobre as expectativas e os resultados das ações das quais participaram no que se refere à sua constituição como educador, apresenta-se o Quadro 4.

Comparando as opiniões de professores em início de atividades do Programa CASa com as dos concludentes, observamos que nos aspectos "saberes pedagógicos" e "interpessoais", há uma semelhança entre seus anseios. Os aspectos indicados sinalizam que o CASa colabora para a construção de saberes pedagógicos (OLIVEIRA, 2015; SAVIANI,1996).

Com relação às contribuições das ações do Programa CASa para constituir conhecimentos pedagógicos, a maioria dos participantes, representada por 34 
Quadro 4. Contribuições de ações para a constituição do bacharel como educador

\begin{tabular}{|c|c|c|}
\hline \multicolumn{3}{|c|}{ Contribuições do programa casa para a constituição do bacharel como educador } \\
\hline Saberes & $\begin{array}{c}\text { Expectativas dos } \\
\text { bacharéis que estavam } \\
\text { participando de ações do } \\
\text { programa casa }\end{array}$ & $\begin{array}{l}\text { Percepções dos bacharéis que concluíram } \\
\text { ações do programa casa }\end{array}$ \\
\hline Pesquisa & Métodos de pesquisa & Fomento à pesquisa \\
\hline Pedagógicos & $\begin{array}{c}\text { Didática } \\
\text { Relação teoria e prática } \\
\text { Conhecimento de } \\
\text { políticas e filosofia de } \\
\text { educação } \\
\text { Enriquecimento das aulas } \\
\text { Conhecimento humano } \\
\text { Processo de ensino } \\
\text { Tecnologia } \\
\text { Avaliação }\end{array}$ & $\begin{array}{c}\text { Técnicas de ensino } \\
\text { Reflexões sobre a prática docente e } \\
\text { exemplos de práticas docentes } \\
\text { Conhecimentos } \\
\text { Estratégia para melhorar a forma como os } \\
\text { conhecimentos podem ser compreendidos } \\
\text { pelos educandos. } \\
\text { Debate acerca de situações de ensino e } \\
\text { aprendizagem } \\
\text { Planejamento de ensino } \\
\text { Tecnologia } \\
\text { Avaliação }\end{array}$ \\
\hline Interpessoais & $\begin{array}{l}\text { Troca de experiências } \\
\text { Troca de ideias } \\
\text { Cooperação entre os } \\
\text { educadores, educandos e } \\
\text { técnico-administrativos }\end{array}$ & $\begin{array}{l}\text { Compartilhamento de vivências } \\
\text { Troca de conhecimentos } \\
\text { Relação educador-educando } \\
\text { Ausência de cooperação }\end{array}$ \\
\hline Aperfeiçoamento & $\begin{array}{l}\text { Capacitação docente } \\
\text { Atualização } \\
\text { Currículo }\end{array}$ & -- \\
\hline
\end{tabular}

Fonte: Elaborado pelos autores (2017)

docentes, considerou que as ações institucionais ofereciam subsídios para produção de saberes docentes; vejamos justificativas elencadas no Quadro 5:

Dos docentes "[...] que egressaram dos cursos de bacharelado, muitos não tiveram disciplinas de apoio didático-pedagógico, seja nos seus cursos de graduação ou nos de pós-graduação." (OLIVEIRA, 2015, p. 35). As justificativas positivas destacam colaboração para elaborar saberes voltados ao desenvolvimento de conhecimentos do educando. $\mathrm{O}$ docente necessita modificar suas ações e métodos de ensino por meio de novos modelos de planejamento, estratégias pedagógicas e processos avaliativos. As ações da UFC possibilitaram uma formação docente direcionada à mudança do paradigma orientador desse processo; isso exige reorientação do ensino e da aprendizagem e organização dos recursos e espaços de trabalho (ALMEIDA; PIMENTA, 2011).

Foram feitas sugestões de melhorias para o Programa CASa. (Quadro 6). 
Quadro 5. Contribuições das ações para a construção de conhecimentos pedagógicos

\begin{tabular}{|l|c|}
\hline Opiniões positivas & Opiniões negativas \\
\hline Debate sobre situações de ensino e aprendizagem & Ausência de conhecimentos \\
Nas ambiências são expostas realidades diferentes já & direcionados à área específica \\
que são professores de cursos e áreas distintas & Pouco referencial metodológico de \\
Relação aluno-professor & técnicas pedagógicas. \\
Planejamento de ensino & \\
Reflexão sobre a prática em sala de aula & \\
Novas técnicas de exposição e avaliação & \\
Didática & \\
Exemplos de práticas docentes & \\
Uso de tecnologias & \\
Pesquisa & \\
\hline
\end{tabular}

Fonte: Elaborado pelos autores (2017).

Quadro 6. Sugestões de melhorias

\begin{tabular}{|l|c|}
\hline $\begin{array}{l}\text { Aspectos } \\
\text { Avaliados }\end{array}$ & $\begin{array}{c}\text { Sugestões } \\
\text { assuntos }\end{array}$ \\
\hline $\begin{array}{c}\text { Eventos e } \\
\text { Promover palestras, eventos que sejam abrangentes a todos os cursos. } \\
\text { Temas relevantes e de ensino. } \\
\text { Diversidade de assuntos. }\end{array}$ \\
\hline Detectar necessidades dos novos docentes por setor.
\end{tabular}

Fonte: Elaborado pelos autores (2017). 
Os docentes entendem a necessidade de participarem de atividades que abordem assuntos de seu interesse e que tais ações podem acontecer em locais onde eles tenham maior facilidade de comparecimento, como, por exemplo, nos centros e faculdades onde atuam. Chama-nos atenção a sugestão de que não haja obrigatoriedade, bem como, a diminuição da carga horária. A obrigatoriedade de cumprir carga horária no programa, no período de estágio probatório, é o principal motivo da participação dos docentes-bacharéis, fato que indica a necessidade de sensibilização acerca da relevância da formação pedagógica. Há opinião de reduzir essa carga horária, entretanto, a atual já não é suficiente. Destacamos a carência de melhor comunicação, bastante citada pelos sujeitos.

Objetivando apontar possibilidades de aperfeiçoamento das ações institucionais analisadas, recorremos às contribuições de Almeida e Pimenta (2011), ao destacarem a importância atribuída à formação, pois se faz necessário(a): a priorização dessa formação nas definições orçamentárias e organizacionais; diversidade de linhas de formação, aglutinando ações nos principais eixos definidos pela instituição; novo modelo de formação universitária, que se refere às ações formativas que lhes servirão de base, de modo a possibilitar mudanças nos objetivos da atuação docente; dimensão coletiva da formação docente, possibilitando a produção, a contextualização e a análise de experiências dos professores, de maneira que sejam compreendidos e trabalhados por todos.

Anastasiou (2011) faz algumas anotações relativas às ações institucionais, com as quais concordamos: constituição de grupos de apoio pedagógicos em programa institucional, como parte do Projeto Político-Institucional, e que perdure além de uma proposta da gestão; atualização dos grupos de apoio pedagógico com vínculos pessoais e institucionais; criação de espaços contínuos nas instituições de formação continuada dos docentes, no sentido da profissionalização para a docência.

\section{Considerações finais: existem contribuições para a constituição do bacharel como educador?}

A realização desta pesquisa possibilitou algumas reflexões conclusivas acerca das contribuições de ações de formação docente institucional para a constituição do bacharel-docente. Por meio da análise documental, observamos que a formação pedagógica para a educação superior é preterida na legislação ao longo de décadas e, mesmo com crescente preocupação de estudiosos da educação e da publicação de pesquisas que apontam a urgência de uma política educacional direcionada a essa formação, pouco tem sido feito para que esse silêncio seja rompido. Essa 
política não pode ser pautada em ações isoladas, mas deve ser definida como política global que valorize a formação e a profissionalização do professor universitário, privilegiando, associadamente, formação inicial, pós-graduação e formação contínua.

As ações de formação docente institucionais são a única alternativa disponível para bacharéis que ingressam na docência universitária. Na UFC, essas iniciativas são desenvolvidas no âmbito de um programa institucionalizado, o Programa $\mathrm{CASa}$. A pesquisa revelou que, entre os principais motivos que levam os docentes bacharéis a participarem do programa CASa, está a obrigatoriedade de cumprir, no período de estágio probatório, carga horária de $64 \mathrm{~h}$. Existe uma preocupação relacionada ao cumprimento desta obrigatoriedade em detrimento de outros motivos, embora declarados pelos participantes, como: adquirir e/ou aperfeiçoar conhecimentos pedagógicos, contribuição para o desenvolvimento profissional docente, troca de experiências com colegas professores, enriquecer o currículo e melhoria da prática docente.

Com relação às contribuições das ações do Programa CASa para a constituição de conhecimentos pedagógicos, a maioria dos participantes considerou que a participação nas atividades foi importante. Entre os sujeitos que afirmaram não perceber colaboração para constituir saberes pedagógicos, foram expostas as seguintes justificativas: ausência de conhecimentos direcionados à área específica e pouco referencial metodológico de técnicas pedagógicas.

A pesquisa empírica apontou aspectos positivos e algumas lacunas nas ações desenvolvidas, atualmente, no universo dessa investigação, que podem estar ocorrendo em outras instituições. Os pontos positivos salientados pelos sujeitos desta pesquisa denotam que a Universidade está na trilha para a consolidação de um programa capaz de contribuir efetivamente para o preenchimento do hiato entre o bacharel e o educador no que se refere à sua formação.

Não obstante, os sujeitos indicaram desafios para melhoria do programa, com destaque para: necessidade de maior diversidade de atividades, horários e locais, ausência de temas sobre ética, pouca contribuição para a constituição de conhecimentos pedagógicos, poucas opções de interesse dos bacharéis, entre outros.

Infere-se, portanto, que as contribuições das ações do Programa CASa para a constituição do docente-bacharel perpassa a construção de conhecimentos pedagógicos, oferecendo subsídios para a produção desses saberes. Porém, existem lacunas relacionadas à ausência de conhecimentos direcionados às necessidades 
específicas do bacharel para que desenvolva saberes da docência. Assim, as ações formativas para a docência realizadas na UFC propiciam mudanças de paradigmas para atuação do bacharel como docente relacionadas à construção de conhecimentos metodológicos nos processos de ensino e aprendizagem.

As políticas institucionalizadas, voltadas para a preparação docente, não são menos ou mais eficientes do que o processo de autoformação, mas precisam ser realizadas paralelamente, de maneira complementar, e cada uma possui sua relevância. É fundamental que a instituição assuma sua parte nessa jornada, visto que tem como papel, entre outros, oferecer ensino de qualidade e, para isso, precisa de um corpo docente detentor não somente de conhecimentos específicos de sua área de atuação, mas também em relação aos aspectos pedagógicos. É necessário que seja dirigido um olhar sobre as questões que envolvem formação docente para o ensino na educação superior, buscando-se elaborar e implementar políticas institucionalizadas de formação para esse profissional. 


\title{
Institutional actions for teachers training: what are the contributions to the development of Bachelors in Teaching?
}

\begin{abstract}
This study aims to evaluate the contributions of institutional actions for teachers training for the development of Bachelors in Teaching. A qualitative investigation and a multiple case study were developed for this research. It employed documental analysis, participant observation and survey as techniques. The study was applied to 37 bachelors in teaching who work at Universidade Federal do Ceará (Brazil). During the process of interpretation of results, the Hermeneutic Content Analysis was used. The main results show that institutional actions for teachers training contribute to the development of Bachelors in Teaching, by offering subsidies to the production of educational knowledge and by providing paradigm shifts in the actions of bachelors as teachers in the teaching-learning process. However, there are lacks related to the specific needs of bachelors that hinder teaching knowledge development
\end{abstract}

Keywords: Teaching education. Institutional actions for teachers training. Bachelor in teaching.

\section{Acciones de formación docente institucionales: ¿cuáles son las contribuciones para la constitución del docente con licenciatura?}

\section{Resumen}

Este estudio tiene por objetivo evaluar las contribuciones de acciones de formación docente institucionales para la constitución del docente licenciado. Se desarrolló una investigación cualitativa y descriptiva y estudio de casos múltiples. Se utilizaron las técnicas análisis documental, observación participante y cuestionario. Participaron de la investigación 37 docentes licenciados que actúan en la Universidad Federal de Ceará (Brasil). En. En el proceso de interpretación de los resultados se recurrió al Análisis Hermenéutico del Contenido. Como principales resultados, se tiene: las acciones de formación docente institucionales colaboran para la constitución del docente licenciado por ofrecer subsidios para la producción de conocimientos pedagógicos y propician cambios de paradigmas para la actuación del licenciado como docente en lo que se refiere a los procesos de enseñanza y aprendizaje. Sin embargo, existen lagunas relacionadas con las necesidades especificas del licenciado para que desarrolle conocimientos de la docencia.

Palabras clave: Formación docente. Acciones de formación docente institucionales. Docente licenciado. 


\section{Referências}

ALMEIDA, M. I. Formação do professor do ensino superior: desafios e políticas institucionais. São Paulo: Cortez, 2012.

ALMEIDA, M.; PIMENTA, S. G. A construção da pedagogia universitária no âmbito da Universidade de São Paulo.

In: PIMENTA, S. G.; ALMEIDA, M. I. (Orgs.). Pedagogia

universitária: caminhos para a formação de professores. São Paulo: Cortez, 2011. p. 19-43.

ANASTASIOU, L. G. C. Processos formativos de docentes universitários: aspectos teóricos e práticos. In: PIMENTA, S. G.; ALMEIDA, M. I. (Orgs.). Pedagogia universitária: caminhos para a formação de professores. São Paulo: Cortez, 2011. p. 44-74.

BARROS, C. M. P.; DIAS, A. M. I. A formação pedagógica de docentes bacharéis na educação superior: construindo o estado da questão. Revista Educação em Questão, Natal, v. 54, n. 40, p. 42-74, jan./abr. 2016. https://doi.org/10.5935/1981-1802.20160003

BARDIN, L. Análise de conteúdo. Lisboa: 70, 2009.

BEHRENS, M. A.; JUNGES, K. S. Formação pedagógica na docência universitária: o que pensam professores pesquisadores portugueses. Revista Diálogo Educacional, Curitiba, v. 18, n. 56, p. 186-208, jan./mar. 2018. https://doi.org/10.7213/1981-416X.18.056.AO01

BRASIL. Lei $\mathrm{N}^{\circ}$ 8.112, de 11 de dezembro de 1990. Dispõe sobre o regime jurídico dos servidores públicos civis da união, das autarquias e das fundações públicas federais. Diário Oficial União, 12 dez. 1990.

. Câmara de Educação Superior. Resolução CNE/CES N ${ }^{\circ} 1$,

de 3 de abril de 2001. Dispõe sobre os cursos de pós-graduação stricto sensu oferecidos no Brasil por instituições estrangeiras, diretamente ou mediante convênio com instituições nacionais. Diário Oficial União, 4 abr. 2001.

. Resolução CNE/CES No 3, de 5 de outubro de 1999. Fixa condições de validade dos certificados de cursos presenciais de especialização. Diário Oficial União, 6 out. 1999. 
BRASIL. Conselho Federal de Educação. Resolução No 12/1983, de 6 de outubro de 1983. Fixa condições de validade dos certificados de cursos de aperfeiçoamento e especialização para o magistério superior, no sistema federal. Diário Oficial União, 7 out. 1983.

. Ministério de Educação. Lei No 9.394, de 20 de dezembro de 1996. Estabelece as diretrizes e bases da educação nacional. Diário Oficial União, 21 dez. 1996.

CÁRIA, N. P.; SILVA, R. A. Pedagogia universitária em construção: desafios e aproximações teóricas. Regae: Revista de Gestão e Avaliação Educacional, Santa Maria, v. 7, n. 15, p. 25-38, maio/ago. 2018. https://doi. org/10.5902/2318133830098

CARNEIRO, S. N. V. et al. A formação e a prática didático-pedagógica do docente bacharel no curso de administração. Revista Diálogo Educacional, Curitiba, v. 18, n. 56, p. 209-30, jan./mar. 2018. https://doi.org/10.7213/1981416X.18.056.AO02

CUNHA, M. I. (Org.). Trajetórias e lugares de formação da docência universitária: da perspectiva individual ao espaço institucional. Araraquara, SP: Junqueira \& Marin, 2010.

FREIRE, P. Pedagogia da autonomia: saberes necessários à prática educativa. 10a ed. Rio de Janeiro, RJ: Paz e Terra, 1996.

. Pedagogia do oprimido. 17. ed. Rio de Janeiro: Paz e terra, 1987.

GASKELL, G. Entrevistas individuais e grupais. In: BAUER, M. W.; GASKELL, G. Pesquisa qualitativa com texto, imagem e som: um manual prático. 4a ed. Petrópolis: Vozes, 2005. p. 64-89.

HERRERA, M. A.; FERNANDÉZ, D. C.; SEGUEL, R. C. Percepción de los profesores sobre integración de TIC en las prácticas de enseñanza en relación a los marcos normativos para la profesión docente en Chile. Ensaio: Avaliação e Políticas Públicas em Educação, Rio de Janeiro, v. 26, n. 98, p. 163-84, jan./ mar. 2018. https://doi.org/10.1590/s0104-40362017002501119

LACERDA, C. R. Saberes necessários à prática docente no ensino superior: olhares dos professores dos cursos de bacharelado. Revista Docência do Ensino Superior, v. 5, n. 2, p. 79-100, out. 2015.

LIBÂNEO, J. C. Didática. 2. ed. São Paulo: Cortez, 2013. 
OLIVEIRA, A. D. A formação didático-pedagógica do professor do ensino superior egresso do bacharelado. Revista Evidência, Araxá, v. 11, n. 11, p. 31-40, 2015.

OLIVEIRA, M. M. Como fazer pesquisa qualitativa. 3. ed. Petrópolis: Vozes, 2010.

OLIVEIRA JÚNIOR, A. P.; LINHARES, M. M. P.; KARWOSKI, A. M. Formação docente no contexto brasileiro das instituições federais de educação superior. Ensaio: Avaliação e Políticas Públicas em Educação, Rio de Janeiro, v. 26, n. 98, p. 52-90, jan./mar. 2018. https://doi.org/10.1590/s010440362018002600902

PALMER, R. Hermenêutica. Lisboa: 70, 2006.

PIMENTA, S. G.; ANASTASIOU, L. G. C. Docência no ensino superior. 5. ed. São Paulo: Cortez, 2014.

SAVIANI, D. Os saberes implicados na formação do educador. In: BICUDO, M. A.; SILVA JUNIOR, C. A. (Orgs.). Formação do educador: dever do estado, tarefa da universidade. São Paulo: Unesp, 1996. p.145-55.

SCHWANDT, T. A. Três posturas epistemológicas para investigação qualitativa: interpretativismo, hermenêutica e construtivismo social. In: DENZIN,N. K.; LINCOLN, Y. S. O planejamento da pesquisa qualitativa: teorias e abordagens. Porto Alegre: Artmed, 2006. p. 193-297.

TARDIF, M. Saberes docentes e formação profissional. 15. ed. Petrópolis: Vozes, 2013.

UNIVERSIDADE FEDERAL DO CEARÁ - UFC. Carta de apresentação: CASa. Fortaleza, 2013.

. Plano de desenvolvimento institucional.

Fortaleza, CE, 2012. Disponível em: <http://www.ufc.br/a-universidade/ documentos-oficiais/313-plano-de-desenvolvimento-institucional-pdi>. Acesso em: 2 ago. 2016.

. Relatório de autoavaliação institucional da Universidade Federal do Ceará (UFC) ano base 2009. Fortaleza, CE, 2010. Disponível em: $<$ http://www.ufc.br/a-universidade/avaliacao-institucional/328-relatorios-deautoavaliacao-institucvallional>. Acesso em: 2 ago. 2016. 
VASCONCELOS, I. C. O. Estudo de casos múltiplos: a vivência de uma pesquisa educacional. In: JESUS, W. F.; CUNHA, C. (Orgs.). A pesquisa em educação no Brasil: novos cenários e novos olhares. Brasília, DF: Liber, 2016.

VASCONCELOS, M. L. A formação do professor do ensino superior. 2. ed. São Paulo: Pioneira, 2000.

VIANNA, H. M. Pesquisa em educação: a observação. Brasília, DF: Liber, 2007.

\section{Informações dos autores}

Conceição de Maria Pinheiro Barros: Doutora em Educação pela Universidade Estadual do Ceará (UECE). Professora Adjunta da Universidade Federal do Ceará (UFC). Líder do Grupo de Pesquisa Estudos e Pesquisas em Secretariado Executivo da UFC. Contato: conceicaompb@ufc.br

(iD) http://orcid.org/0000-0002-4515-5829

Ana Maria Iorio Dias: Doutora em Educação pela Universidade Federal do Ceará. Possui pós-Graduação em Educação pela Universidade de Brasília (UNB). Professora colaboradora do Programa de Pós-Graduação em Educação (Mestrado e Doutorado) da Universidade Estadual do Ceará (UECE), na Linha de Pesquisa sobre Formação e Desenvolvimento Profissional em Educação. Líder do Grupo de Pesquisa Formação de Professores. Contato: ana.iorio@yahoo.com.br

(iD) http://orcid.org/0000-0001-8896-6966

Augusto Cezar de Aquino Cabral: Doutor em Administração pela Universidade Federal de Minas Gerais (UFMG). Professor Titular da Universidade Federal do Ceará (UFC). Professor titular do Programa de Pós-graduação em Administração e Controladoria (PPAC) da UFC. Líder do Grupo de Pesquisa Estudos e Pesquisas em Secretariado Executivo da UFC. Contato: cabral@ufc.br

(iD) http://orcid.org/0000-0001-8248-4886 